\title{
Reduced item set for the amyotrophic lateral sclerosis assessment questionnaire: development and validation of the ALSAQ-5
}

\author{
C Jenkinson, R Fitzpatrick
}

\begin{abstract}
Objective-The 40 item amyotrophic lateral sclerosis assessment questionnaire (ALSAQ-40) is a subjective health measure designed specifically to assess areas of importance to patients with ALS. It was designed for use in surveys and clinical trials of this patient group, and has been assessed for reliability and validity. Despite its relative brevity there are situations where an even shorter form of the instrument would be desirable. Consequently, this paper reports a process of item reduction which results in a brief five item version of the instrument.

Methods-Data from two surveys of patients with ALS who completed the ALSAQ-40 were analysed to develop a short form ALSAQ. Questionnaire items were correlated with their dimension total scores. Highly correlated items were transformed onto a scale from 0 to 100 and results compared with the parent dimension.

Results-Five items were selected that produced results that closely resembled those of the five dimension scores of the ALSAQ-40.

Conclusions-Results on the new measure compared with the parent ("gold standard") ALSAQ-40 suggest that the measure can produce similar results to the longer form but with considerable economy. (F Neurol Neurosurg Psychiatry 2001;70:70-73)
\end{abstract}

Keywords: amyotrophic lateral sclerosis specific measure; health status; ALSAQ-40; ALSAQ-5

Picker Institute Europe, King's Mead House, Oxpens Road, Oxford OX1 1JX, UK C Jenkinson

Health Services Research Unit, Department of Public Health, University of Oxford, Institute of Health Sciences, Headington, Oxford, OX3 7LF, UK

C Jenkinson

Department of Public Health

R Fitzpatrick

Correspondence to: Dr C Jenkinson crispin.jenkinson@ dphpc.ox.ac.uk

Received 2 June 2000 Accepted 16 August 2000 \section{that they assess areas of particular salience to} patients and are likely to be sensitive to changes which are central to their concerns. ${ }^{2}$ The introduction of the 40 item ALS assessment questionnaire (ALSAQ-40) has made available for the first time a rigorously designed and validated subjective health status measure that can be used to evaluate the impact of treatment regimes on patients.
The ALSAQ-40 questionnaire was designed on the basis of in depth interviews with patients, which generated a large initial list of questionnaire items from which a 78 item measure was developed. This instrument was evaluated in surveys of patients with ALS. Statistical analysis of these data produced a final 40 item questionnaire. This contains five dimensions of subjective health status: physical mobility, activities of daily living and independence, eating and drinking, communication, and emotional reactions. The psychometric properties of the measure, together with a copy of the scale, have been documented in full. ${ }^{3}$

Despite the relative brevity of the ALSAQ-40 there are situations in which an even shorter instrument is desirable. Certainly, in the case of large scale trials it has been suggested that there is a greater chance of patient and physician participation when the data required are simple to collect and relatively brief. Indeed, the quality of recorded data in trials often suffers when too many data are collected on each patient. ${ }^{4}$ Furthermore, it is evidently desirable to reduce patient burden in data collection, especially when the demands of the illness can be considerable, as in neurological disorders such as ALS. The purpose of this paper, therefore, is to report on the development of a short form ALSAQ which may be used in large scale studies when the ALSAQ-40 is thought to be unpracticable.

Many attempts to reduce the length of instruments ignore, or at least do not report, appropriate methodological and statistical procedures. $^{5}$ Most importantly, the choice of instrument for item reduction is usually inappropriate because there is little or no evidence for the reliability and validity of the original measure. Manifestly reducing the length of an instrument that is unreliable is not a worthwhile exercise. In this instance the ALSAQ-40 has proved validity and reliability and consequently is used as the "gold standard" for consequent item reduction. Results on any short form should produce results that are as close as possible to those of the long form. This paper documents the methods used to select items for a shorter version of the ALSAQ-40 and compares results between the two versions of the instrument.

\section{Methods}

MOTOR NEURON DISEASE ASSOCIATION SURVEY Items for inclusion in the shortened form of the ALSAQ were derived from a data set that included the ALSAQ-40. This was a survey of the needs of patient members of the MND 
Table 1 Descriptive statistics for the five ALSAQ-40 domains and individual items (standardised to a score of $0-100$ )

\begin{tabular}{|c|c|c|c|c|c|}
\hline Variable name & $n$ & $\begin{array}{l}25 \text { th } \\
\text { percentile }\end{array}$ & Median & $\begin{array}{l}75 \text { th } \\
\text { percentile }\end{array}$ & Mean (SD) \\
\hline Physical mobility* & 144 & 52.5 & 71.25 & 100 & $69.88(26.78)$ \\
\hline MOB-1 & 146 & 50 & 75 & 100 & $72.43(33.70)$ \\
\hline MOB-2 & 146 & 0 & 50 & 100 & $54.62(41.83)$ \\
\hline MOB-3 & 146 & 50 & 75 & 100 & $63.36(35.25)$ \\
\hline MOB-4 & 145 & 25 & 75 & 100 & $62.24(37.16)$ \\
\hline MOB-5 & 146 & 75 & 100 & 100 & $81.34(26.23)$ \\
\hline MOB-6 & 146 & 75 & 75 & 100 & $77.23(27.37)$ \\
\hline MOB-7 & 146 & 0 & 75 & 100 & $57.36(41.75)$ \\
\hline MOB-8 & 146 & 75 & 100 & 100 & $85.45(23.99)$ \\
\hline MOB-9 & 146 & 50 & 75 & 100 & $71.58(29.31)$ \\
\hline MOB-10 & 145 & 50 & 75 & 100 & $76.03(26.98)$ \\
\hline ADL/Independence ${ }^{\star}$ & 142 & 47.5 & 72.5 & 97.5 & $69.42(26.41)$ \\
\hline ADL-11 & 146 & 50 & 75 & 100 & $69.01(29.70)$ \\
\hline ADL-12 & 145 & 50 & 75 & 100 & $72.59(29.80)$ \\
\hline ADL-13 & 146 & 50 & 75 & 100 & $73.63(26.87)$ \\
\hline ADL-14 & 146 & 50 & 75 & 100 & $64.04(33.73)$ \\
\hline ADL-15 & 146 & 50 & 75 & 100 & $71.92(32.28)$ \\
\hline ADL-16 & 146 & 75 & 100 & 100 & $84.42(22.39)$ \\
\hline ADL-17 & 145 & 25 & 50 & 100 & $54.83(39.67)$ \\
\hline ADL-18 & 145 & 25 & 75 & 100 & $60.00(39.35)$ \\
\hline ADL-19 & 145 & 50 & 100 & 100 & $78.10(27.46)$ \\
\hline ADL-20 & 145 & 50 & 75 & 100 & $66.55(36.94)$ \\
\hline Eating and drinking ${ }^{\star}$ & 145 & 0 & 33.33 & 62.5 & $37.93(32.73)$ \\
\hline EAT-21 & 145 & 0 & 50 & 75 & $41.21(33.53)$ \\
\hline EAT-22 & 145 & $\mathbf{0}$ & 25 & 75 & 39.14 (36.78) \\
\hline EAT-23 & 145 & 0 & 25 & 50 & $33.45(34.89)$ \\
\hline Communication ${ }^{\star}$ & 144 & 7.14 & 53.57 & 92.86 & $50.30(40.58)$ \\
\hline $\mathrm{COM}-24$ & 145 & 0 & 50 & 100 & $48.45(41.38)$ \\
\hline COM-25 & 145 & $\mathbf{0}$ & 50 & 100 & $50.86(42.02)$ \\
\hline COM-26 & 145 & 0 & 50 & 100 & $46.21(43.43)$ \\
\hline $\mathrm{COM}-27$ & 145 & 0 & 50 & 100 & $52.59(43.87)$ \\
\hline $\mathrm{COM}-28$ & 144 & 0 & 75 & 100 & $55.38(43.87)$ \\
\hline COM-29 & 145 & 0 & 50 & 100 & $51.21(44.42)$ \\
\hline $\mathrm{COM}-30$ & 145 & 0 & 50 & 100 & $49.14(44.04)$ \\
\hline Emotional reactions ${ }^{\star}$ & 143 & 32.5 & 50 & 70 & $50.59(24.88)$ \\
\hline EM-31 & 145 & 0 & 50 & 75 & $41.55(35.99)$ \\
\hline EM-32 & 145 & 0 & 50 & 75 & $43.62(33.17)$ \\
\hline EM-33 & 147 & 25 & 50 & 75 & $48.30(35.31)$ \\
\hline EM-34 & 147 & 25 & 50 & 75 & $53.23(32.88)$ \\
\hline EM-35 & 147 & 50 & 75 & 100 & $63.61(29.58)$ \\
\hline EM-36 & 147 & 0 & 50 & 75 & $42.35(35.43)$ \\
\hline EM-37 & 147 & 25 & 50 & 75 & $46.26(36.47)$ \\
\hline EM-38 & 145 & 25 & 50 & 75 & $46.55(29.85)$ \\
\hline EM-39 & 147 & 50 & 75 & 100 & $64.46(28.21)$ \\
\hline EM-40 & 147 & 25 & 50 & 100 & $58.16(34.27)$ \\
\hline
\end{tabular}

Bold indicates items selected for ALSAQ- 5 .

* Scale score from full 40 item ALSAQ-40.

Table 2 Descriptive statistics for the five dimensions of the ALSA-40 and ALSAQ-5 (denoted by the prefix "mini") for the MND Association and MND regional surveys

\begin{tabular}{llll}
\hline & Mean (SD) & $95 \%$ CI & $n$ \\
\hline MND Association survey: & & & \\
Physical mobility & $69.88(26.78)$ & $65.5-74.3$ & 144 \\
Mini-MOB & $71.58(29.31)$ & $66.8-76.4$ & 146 \\
ADL/independence & $69.42(26.41)$ & $65.0-73.8$ & 142 \\
Mini-ADL & $69.01(29.70)$ & $64.2-73.9$ & 146 \\
Eating and drinking & $37.93(32.72)$ & $32.6-43.3$ & 145 \\
Mini-EAT & $39.14(36.78)$ & $33.1-45.2$ & 145 \\
Communication & $50.30(40.58)$ & $43.6-57.0$ & 144 \\
Mini-COM & $50.86(42.02)$ & $44.0-57.8$ & 145 \\
Emotional reactions & $50.59(24.88)$ & $46.5-54.7$ & 143 \\
Mini-EM & $53.23(32.88)$ & $47.9-58.6$ & 147 \\
MND Regional survey: & & & \\
Physical mobility & $67.84(28.63)$ & $63.5-72.2$ & 168 \\
Mini-MOB & $66.81(34.81)$ & $64.6-69.1$ & 171 \\
ADL/independence & $69.39(28.23)$ & $65.1-73.7$ & 168 \\
Mini-ADL & $72.11(30.72)$ & $67.5-76.7$ & 173 \\
Eating and drinking & $39.42(32.04)$ & $34.6-44.3$ & 171 \\
Mini-EAT & $40.70(35.77)$ & $35.3-46.1$ & 172 \\
Communication & $49.37(38.32)$ & $43.6-55.2$ & 169 \\
Mini-COM & $48.11(42.32)$ & $41.7-54.5$ & 172 \\
Emotional reactions & $48.04(26.40)$ & $44.0-52.0$ & 170 \\
Mini-EM & $50.44(34.45)$ & $45.2-55.6$ & 171 \\
\hline
\end{tabular}

Association of the United Kingdom which also included the ALSAQ-40 and questions on demographic details. Patients were excluded from this survey if they had an uncertain diagnosis or were close to death. Consequently, 250 of the remaining members were randomly selected from the MND Association database and received the questionnaire together with a covering letter from the MND Association. No follow up was undertaken, as it was possible that people may die between the mailings and a repeat questionnaire from the MND Association could cause distress to relatives.

MOTOR NEURON DISEASE REGIONAL SURVEY

The results gained from the MND Association survey were compared with those of another large scale survey which included the ALSAQ-40 and the SF-36. ${ }^{6}$ The SF-36 is a generic measure which can yield two summary scores - the physical component summary (PCS) score and the mental component summary (MCS) scores. ${ }^{7}$ Results on the ALSAQ-40 and the shortened form ALSAQ were compared with results on the PCS/MCS. These data came from a postal survey in which care advisors for regions of the Motor Neuron Disease Association Society in England, Wales, and Northern Ireland were approached for help in recruiting. They provided names and addresses of patients with ALS/MND. However, a few patients $(n=25)$ were not contacted in this way but volunteered to take part in the study, which had been outlined in a copy of Thumbprint, the United Kingdom MND Association newsletter. Including these 25 people the questionnaire was mailed to a total of 208 patients.

\section{STATISTICAL ANALYSES}

The MND association survey was used to determine which items should be included in a shortened version of the ALSAQ. Scores were calculated for the five dimensions of the ALSAQ-40, on a standard scale of 0 (best possible health state measured by the ALSAQ) to 100 (worst possible health state measured by the ALSAQ). Furthermore, all 40 items on the questionnaire were transformed onto a scale from 0 to 100, and each item compared with its dimension total. Items with mean scores not found to be significantly different from their scale total, and which most closely reflected the distribution of the scale were selected for inclusion in the short form measure; $95 \%$ confidence intervals (95\% CIs) were calculated for each scale and item representing the scale in the short form five item ALSAQ (referred to here as ALSAQ-5). Each selected item was then correlated with the five scale scores, to ensure that it was both highly associated with the (uncorrected) scale score to which it contributes, and, further, was less well correlated with the other four scales.

The operating characteristics of the two measures was then assessed on the MND regional survey. Firstly, correlations of items to scale scores were undertaken again on this dataset to corroborate the results found from the MND Association survey. The ALSAQ-40 and ALSAQ-5 scores were then correlated with the SF-36 PCS and MCS to determine whether a similar pattern of associations was seen. It was hypothesised that if the operating characteristics of the two versions of the instrument are similar then the patterns of correlations between ALSAQ-5 items and the 
Table 3 Correlations (Spearman) of ALSAQ-5 items (denoted by prefix "Mini") with dimensions of the ALSAQ-40 for the MND association survey

\begin{tabular}{|c|c|c|c|c|c|}
\hline & Mini-mob & Mini-ADL & Mini-eat & Mini-com & Mini-em \\
\hline \multirow[t]{2}{*}{ Physical mobility } & $0.81^{\star \star}$ & $0.32^{\star \star}$ & 0.06 & 0.05 & 0.10 \\
\hline & $n=144$ & $\mathrm{n}=141$ & $\mathrm{n}=141$ & $n=141$ & $\mathrm{n}=143$ \\
\hline \multirow[t]{2}{*}{ ADL/independence } & $0.62^{\star \star}$ & $0.79 \star \star$ & $0.18^{\star}$ & 0.09 & 0.14 \\
\hline & $n=142$ & $n=142$ & $n=141$ & $n=142$ & $\mathrm{n}=142$ \\
\hline \multirow[t]{2}{*}{ Eating and drinking } & 0.02 & 0.09 & $0.95^{\star \star}$ & $0.71^{\star \star}$ & $0.33^{\star \star}$ \\
\hline & $n=143$ & $n=143$ & $n=145$ & $\mathrm{n}=144$ & $\mathrm{n}=144$ \\
\hline \multirow{2}{*}{ Communication } & 0.03 & 0.06 & $0.63^{\star \star \star}$ & $0.94 \star \star$ & $0.38^{\star \star}$ \\
\hline & $\mathrm{n}=142$ & $\mathrm{n}=142$ & $n=143$ & $n=144$ & $\mathrm{n}=144$ \\
\hline \multirow[t]{2}{*}{ Emotional reactions } & 0.11 & 0.11 & $0.34^{\star \star}$ & $0.41^{\star \star}$ & $0.85^{\star \star}$ \\
\hline & $\mathrm{n}=141$ & $\mathrm{n}=141$ & $\mathrm{n}=142$ & $\mathrm{n}=143$ & $n=143$ \\
\hline
\end{tabular}

Bold indicates correlation of parent scale with item.

Table 4 Correlations (Spearman) of ALSAQ-5 items (denoted by prefix "Mini") with dimensions of the $A L S A Q-40$ for the MND regional survey

\begin{tabular}{|c|c|c|c|c|c|}
\hline & Mini-Mob & Mini-ADL & Mini-eat & Mini-com & Mini-Em \\
\hline Physical mobility & $\begin{array}{l}0.84 \star \star \\
n=168\end{array}$ & $\begin{array}{l}0.34^{\star \star} \\
\mathrm{n}=168\end{array}$ & $\begin{array}{l}0.10 \\
\mathrm{n}=167\end{array}$ & $\begin{array}{l}0.12 \\
\mathrm{n}=166\end{array}$ & $\begin{array}{l}0.25^{\star \star} \\
\mathrm{n}=165\end{array}$ \\
\hline ADL/independence & $\begin{array}{l}0.56^{\star \star} \\
\mathrm{n}=167\end{array}$ & $\begin{array}{l}0.84^{\star \star} \\
n=168\end{array}$ & $\begin{array}{l}0.11^{\star} \\
\mathrm{n}=168\end{array}$ & $\begin{array}{l}0.11 \\
\mathrm{n}=172\end{array}$ & $\begin{array}{l}0.23^{\star \star} \\
\mathrm{n}=166\end{array}$ \\
\hline Eating and drinking & $\begin{array}{l}0.09 \\
n=169\end{array}$ & $\begin{array}{l}0.06 \\
\mathrm{n}=170\end{array}$ & $\begin{array}{l}0.94 \star \star \\
n=171\end{array}$ & $\begin{array}{l}0.72^{\star \star} \\
\mathrm{n}=169\end{array}$ & $\begin{array}{l}0.24^{\star \star} \\
\mathrm{n}=1168\end{array}$ \\
\hline Communication & $\begin{array}{l}0.15 \\
n=168\end{array}$ & $\begin{array}{l}0.03 \\
n=169\end{array}$ & $\begin{array}{l}0.68^{\star \star} \\
\mathrm{n}=168\end{array}$ & $\begin{array}{l}0.93 \star \star \\
n=169\end{array}$ & $\begin{array}{l}0.28^{\star \star} \\
\mathrm{n}=166\end{array}$ \\
\hline Emotional reactions & $\begin{array}{l}0.27^{\star \star} \\
\mathrm{n}=167\end{array}$ & $\begin{array}{l}0.14 \\
\mathrm{n}=169\end{array}$ & $\begin{array}{l}0.36^{\star \star} \\
\mathrm{n}=171\end{array}$ & $\begin{array}{l}0.25^{\star \star} \\
\mathrm{n}=168\end{array}$ & $\begin{array}{l}0.83^{\star \star} \\
n=170\end{array}$ \\
\hline
\end{tabular}

Bold indicates correlation of parent scale with item.

PCS and MCS should closely resemble the pattern of correlations found between the dimensions of the ALSAQ- 40 and the PCS and MCS.

\section{Results}

MOTOR NEURON DISEASE ASSOCIATION SURVEY

One hundred and forty nine $(59.6 \%)$ of the questionnaires were returned. Ninety seven $(65.1 \%)$ of the respondents were men and 52 $(34.9 \%)$ were women. The mean age of respondents was 62.38 (SD 12.65) years (youngest 28, oldest 89 years). Twenty nine $(19.5 \%)$ respondents had had the diagnosis of MND/ALS for 2 years or less, whereas 89 $(59.8 \%)$ had had their diagnosis for 5 years or less. Seventy respondents $(47.0 \%)$ indicated they had received help from someone else to complete the questionnaire. Five items were found to produce results, once standardised to the $0-100$ scoring system of the parent questionnaire, which produced very similar descriptive statistics to the five respective scales from which they were extracted (table 1); $95 \%$ confidence intervals were calculated which

Table 5 Correlation (Spearman) of ALSAQ-40 dimensions and ALSAQ-5 items (denoted by prefix "Mini") with SF-36 mental component summary score (MCS) and SF-36 physical component summary score (PCS)

\begin{tabular}{lll}
\hline & \multicolumn{1}{l}{$M C S$} & PCS \\
\hline Physical mobility & $-0.15, \mathrm{n}=62$ & $-0.46, \mathrm{n}=62^{\star \star}$ \\
Mini-MOB & $-0.09, \mathrm{n}=62$ & $-0.33, \mathrm{n}=62^{\star \star}$ \\
ADL/independence & $0.16, \mathrm{n}=62$ & $-0.39, \mathrm{n}=62^{\star \star}$ \\
Mini-ADL & $0.05, \mathrm{n}=62$ & $-0.31, \mathrm{n}=62^{\star \star}$ \\
Eating and drinking & $-0.28, \mathrm{n}=62^{\star}$ & $-0.01, \mathrm{n}=62$ \\
Mini-EAT & $-0.27, \mathrm{n}=62^{\star}$ & $-0.04, \mathrm{n}=62$ \\
Communication & $-0.40, \mathrm{n}=61^{\star}$ & $0.03, \mathrm{n}=61$ \\
Mini-COM & $-0.30, \mathrm{n}=62^{\star}$ & $0.03, \mathrm{n}=62$ \\
Emotional reactions & $-0.70, \mathrm{n}=60^{\star \star \star}$ & $-0.12, \mathrm{n}=60$ \\
Mini-EM & $-0.63, \mathrm{n}=60^{\star \star \star}$ & $-0.05, \mathrm{n}=62$ \\
\hline
\end{tabular}

${ }^{\star}$ Correlation significant at the 0.05 level; ${ }^{\star \star}$ Correlation significant at the 0.01 level; ${ }^{\star \star \star}$ Correlation significant at the 0.01 level. indicated that the item scores overlapped considerably with the scale scores (table 2).

The five selected items of the ALSAQ- 5 were correlated with all five dimensions scores on the ALSAQ-40 (table 3). Items were found to be correlated the most highly with the parent dimension from which they were extracted.

MOTOR NEURON DISEASE REGIONAL SURVEY A response rate of $173(83.2 \%)$ was achieved. The mean age of the sample was 62.6 (SD 12.5 ) years ( youngest 31 , oldest $92, \mathrm{n}=168$ ). Sixty six $(38.2 \%)$ of the sample were women and $104(60.1 \%)$ men. Eighty nine (53\%) respondents reported that they had had the diagnosis of MND/ALS for 2 years or less, whereas $140(83.3 \%)$ had had their diagnosis for 5 years or less. Eighty one respondents

Table 6 Dimensions and items of the ALSAQ-40 and ALSAQ-5 (in italics)

\begin{tabular}{|c|c|c|}
\hline Scale & $\begin{array}{l}\text { Item No on } \\
A L S A Q-40\end{array}$ & Items \\
\hline \multicolumn{3}{|c|}{ Physical mobility (MOB): } \\
\hline & 1 & $\begin{array}{l}\text { Difficulty walking short } \\
\text { distances }\end{array}$ \\
\hline & 2 & Fallen whilst walking \\
\hline & 3 & $\begin{array}{l}\text { Stumbled or tripped whilst } \\
\text { walking }\end{array}$ \\
\hline & 4 & Lost balance whilst walking \\
\hline & 5 & Concentrate when walking \\
\hline & 6 & Tired when walking \\
\hline & 7 & Pains in legs whilst walking \\
\hline & 8 & $\begin{array}{l}\text { Difficulty going up and down } \\
\text { stairs }\end{array}$ \\
\hline & 9 & Difficulty standing $u p$ \\
\hline & 10 & $\begin{array}{l}\text { Difficulty getting up out of } \\
\text { chairs }\end{array}$ \\
\hline \multicolumn{3}{|c|}{ Adl/independence (ADL): } \\
\hline & 11 & $\begin{array}{l}\text { Difficulty using arms and } \\
\text { hands }\end{array}$ \\
\hline & 12 & $\begin{array}{l}\text { Difficulty turning and } \\
\text { moving in bed }\end{array}$ \\
\hline & 13 & Difficulty picking things up \\
\hline & 14 & $\begin{array}{l}\text { Difficulty holding books and } \\
\text { turning pages }\end{array}$ \\
\hline & 15 & Difficulty writing clearly \\
\hline & 16 & $\begin{array}{l}\text { Difficulty doing jobs around } \\
\text { the house }\end{array}$ \\
\hline & 17 & Difficulty feeding myself \\
\hline & 18 & Difficulty combing hair \\
\hline & 19 & Difficulty getting dressed \\
\hline & 20 & $\begin{array}{l}\text { Difficulty washing at hand } \\
\text { basin }\end{array}$ \\
\hline \multicolumn{3}{|c|}{ Eating and drinking (EAT): } \\
\hline & 21 & Difficulty swallowing \\
\hline & 22 & Difficulty eating solid food \\
\hline & 23 & Difficulty drinking liquids \\
\hline \multicolumn{3}{|c|}{ Communication (COM): } \\
\hline & 24 & $\begin{array}{l}\text { Difficulty participating in } \\
\text { conversations }\end{array}$ \\
\hline & 25 & Speech not easy to understand \\
\hline & 26 & $\begin{array}{l}\text { Slurred or stuttered whilst } \\
\text { speaking }\end{array}$ \\
\hline & 27 & Have to talk slowly \\
\hline & 28 & Talked less than I used to do \\
\hline & 29 & Frustrated by speech \\
\hline & 30 & $\begin{array}{l}\text { Felt self conscious about } \\
\text { speech }\end{array}$ \\
\hline \multicolumn{3}{|c|}{ Emotional reactions (EM): } \\
\hline & 31 & Felt lonely \\
\hline & 32 & Felt bored \\
\hline & 33 & $\begin{array}{l}\text { Felt embarrassed in social } \\
\text { situations }\end{array}$ \\
\hline & 34 & Felt hopeless about the future \\
\hline & 35 & $\begin{array}{l}\text { Worried that I was a burden } \\
\text { to others }\end{array}$ \\
\hline & 36 & Wondered why I kept going \\
\hline & 37 & $\begin{array}{l}\text { Felt angry because of the } \\
\text { disease }\end{array}$ \\
\hline & 38 & Felt depressed \\
\hline & 39 & $\begin{array}{l}\text { Worried how disease will } \\
\text { affect my future }\end{array}$ \\
\hline & 40 & Felt as if I had no freedom \\
\hline
\end{tabular}


$(46.0 \%)$ indicated that they had received help from someone else to complete the questionnaire. Mean scores on the five dimensions of the ALSAQ-40 and the five items of the ALSAQ-5 were computed (table 2). No significant differences were found between the scores when both were standardised onto a scale of $0-100$. The five selected items of the ALSAQ-5 were correlated with all five dimension scores on the ALSAQ-40. Once again, items were found to be correlated the most highly with their parent dimension (table 4).

Results on the ALSAQ- 5 and ALSAQ-40 were correlated with the SF-36 PCS and MCS summary scores (table 5). Similar magnitudes of correlation were found with the summary scores whether they were correlated with the ALSAQ-40 dimensions or ALSAQ-5 items. This suggests that the operating characteristics of the ALSAQ-5 items are similar to those of the ALSAQ-40-dimensions. The five items selected for inclusion in the ALSAQ-5, as well as the 40 items of the original questionnaire, are shown in table 6 .

\section{Discussion}

Amyotrophic lateral sclerosis has substantial consequences in terms of impairment and disability. Those with the disorder may experience wide ranging adverse effects to their quality of life. Until recently systematic attempts to assess ALS have focused on standardising clinical findings and ratings of symptoms. ${ }^{8}$ However, all such scales are limited in that observer based rating scales may relate only weakly to the patients' experience of the disease. The development of an ALS specific measure allows for a more complete picture of the impact of the disease on patients' lives. The ALSAQ-40 has been shown to have high levels of reliability and validity and as such should be a valuable addition to outcomes assessment in this area. However, even a relatively brief instrument such as the ALSAQ-40 is not practicable for all purposes. To this end one item was selected from each dimension which most closely duplicates the results gained from the multi-item scale score, but does so with considerable economy. The very high levels of internal reliability of the original scales would suggest that each is tapping a meaningful underlying construct, and the close association of results on the five items of the ALSAQ-5 with their respective dimension on the ALSAQ-40 would suggest that the shortened instrument is providing a similar picture of the disease. The ALSAQ-5 would therefore seem to be a useful measure for surveys or trials in which a short disease specific measure is needed. There is less evidence that the instrument would be useful to assess health status over time at the level of the individual patient in an accurate manner. However, it may prove a useful adjunct to the clinical interview in a similar way that the COOP charts $^{9}$ have been suggested as useful in general practice..$^{10}$ The COOP charts consist of nine items. Each item is related to a health related area of wellbeing, such as emotional wellbeing, social functioning, mobility, etc. The Dartmouth Group suggest that these measures can be handed out in busy clinicians' waiting rooms and be rapidly and easily completed by patients. The charts are then returned to the physician. No scoring algorithms are required and physicians can directly ask questions relating to what is completed on the cards. It has been suggested that such simple methods can dramatically influence doctor-patient communication. ${ }^{11}$ It is possible that the ALSAQ-5 may also find this use. Further research is required in this area to determine how useful such data presented to clinicians would really be, and also to assess the reliability of single items for use in this manner.

The ALSAQ-5 provides a brief assessment of the impacts of ALS/MND upon patients which closely reflects results of the longer form ALSAQ-40. In instances where the 40 item measure is regarded as not practicable then the ALSAQ-5 may be the instrument of choice. Copies of the instrument are available from CJ.

1 Jenkinson C, Swash M, Fitzpatrick R, et al. The European amyotrophic lateral sclerosis health profile study. 7 Neurol Sci 1998;160(suppl 1):122-6.

2 Jenkinson C, Fitzpatrick R, Brennan C, et al. Development and validation of short measure of health status for individuals with ALS/MND: The ALSAQ-40. $\mathcal{F}$ Neurol 1999;246(suppl 3): 16-21.

3 Jenkinson C, Fitzpatrick R, Brennan C, et al. Evidence for the validity and reliability of the ALS assessment que validity and reliability of the ALS assessment
ques the ALSAQ-40. Amyotrophic Lateral Sclerosis questionnaire: the ALSAQ-40. Amyotrophic Lateral

and Other Motor Neurone Diseases 1999;1:33-40.
4 Pocock SJ. Clinical trials: a practical approach. Chichester: John Wiley, 1983.

5 Coste J, Guillemin F, Pouchot J, et al. Methodological approaches to shortening composite measurement scales. $\mathcal{F}$ Clin Epidemiol 1997;50:247-52.

6 Jenkinson C, Fitzpatrick R, Levvy G, et al. The ALSAQ-40. Tests of data quality, score reliability and response rate in a survey of patients. $\mathcal{F}$ Neurol Sci (in press).

7 Ware JE, Kosinski M, Keller S. SF-36 Physical and mental health summary scales: a user manual. Boston, Massachusetts: The Health Institute, New England Medical Center, 1994.

8 Jenkinson C, Fitzpatrick R, Swash M. Amyotrophic lateral sclerosis/motor neurone disease. In: Jenkinson C, Fitzsclerosis/motor neurone disease. In: Jenkinson C, Fitz-
patrick R, Jenkinson D. Health status measurement in neuropatrick R, Jenkinson D. Health status measurement in neuro-

9 Beaufait DW, Nelson EC, Landgraf JM, et al. COOP measures of functional status. In: Stewart M, Tudiver F, Bass $\mathrm{MJ}$, et al, eds. Research methods for primary care. Vol 2. Tools for primary care research. London: Sage, 1992.

10 Nelson EC, Landgraf JM, Hays RD, et al. The functional status of patients: how can it be measured in physicians' offices? Med Care 1990;28:1111-26.

11 Wasson J, Keller A, Rubenstein L, et al. Benefits and obstacles of health status assessment in ambulatory settings: the clinicians point of view. Med Care 1992;30(suppl):MS42-9. 